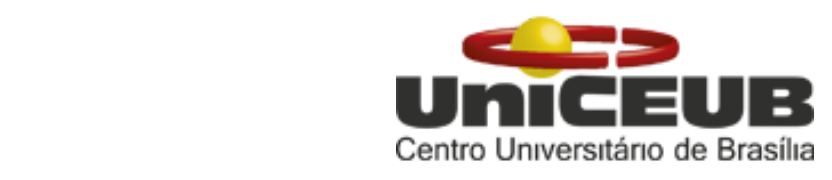

CENTRO UNIVERSITÁRIO DE BRASÍLIA - UnICEUB PROGRAMA DE INICIAÇÃO CIENTÍFICA

LEONARDO RUBINGER BETTI

RENATA NOLÊTO BORGES

OCORRÊNCIA DE MICROFILÁRIA EM CÃES DOMÉSTICOS NO DISTRITO FEDERAL

BRASÍLIA

2019 


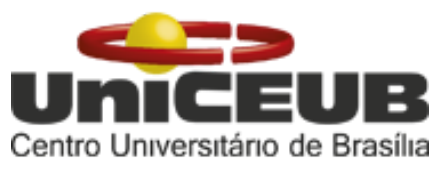

\author{
RENATA NOLÊTO BORGES \\ LEONARDO RUBINGER BETTI \\ BRUNO ALVARENGA DOS SANTOS \\ GLAUCIA MANSUR BALSAMÃO DIAS \\ MARIANA GOMES MARTIN
}

\title{
OCORRÊNCIA DE MICROFILÁRIA EM CÃES DOMÉSTICOS NO DISTRITO FEDERAL
}

Relatório final de pesquisa de Iniciação Científica apresentado à Assessoria de Pós-Graduação e Pesquisa.

Orientação: Bruno Alvarenga dos Santos Carlos A. da Cruz Júnior 
BRASÍLIA

2019

Sumário

Resumo 3

Introdução $\quad 4$

Fundamentação Teórica $\quad 6$

$\begin{array}{ll}\text { Metodologia } & 7\end{array}$

$\begin{array}{lc}\text { Resultados } & 8\end{array}$

Discussão e conclusão $\quad 8$

$\begin{array}{ll}\text { Referências Bibliográficas } & 10\end{array}$ 


\section{Resumo}

Este estudo teve como objetivo verificar a ocorrência da Dirofilariose canina no Distrito Federal em sua fase de microfilária (L1). A dirofilariose é conhecida popularmente como "verme do coração" ou heartworm, que é uma antropozoonose grave e potencialmente fatal, causada por um helminto da espécie Dirofilaria Immitis, gênero Dirofilaria, transmitida por hospedeiros intermediários da família culicidae. A forma infectante do parasito é a fase larval (L1), conhecida por microfilária. Esta é mais frequente em ambientes urbanos por estes possuírem micro-climas quentes e úmidos, que favorecem a reprodução dos mosquitos. Este estudo da ocorrência de microfilária pela técnica de microhematócrito, deu-se em virtude desta doença ser pouco estudada e negligenciada no Brasil e por não se ter localizado trabalhos que abordem este tema na região do Distrito Federal. Foram analisadas 1087 amostras de sangue de cão doméstico sem distinção de sexo, idade, raça e localidade as quais foram doadas pelo laboratório de exames Santé, localizado em Brasília. O material doado entregue em tubos eppendorf identificados e analisadas de 1 a 7 dias entre a recepção no laboratório doador e a análise pela equipe deste projeto. Após a análise das amostras foram identificadas 5 amostras de microfilária $(0,45 \%)$. Não foram localizado outros levantamentos sobre este parasita no Distrito Federal, o que impediu o confronto de resultados, todavia destaca-se a importância de novos estudos que aprofundem o levantamento da fase larval L1 ou de outro estágio da Dirofilaria Immitis, no Distrito Federal.

Palavras-chave: Dirofilariose. Microhematócrito. Distrito Federal. 


\section{Introdução}

A dirofilariose é uma doença grave e potencialmente fatal, considerada uma antropozoonose que emerge dos cães (SILVA, 2014), causada por um helminto da espécie Dirofilaria Immitis, gênero Dirofilaria, ordem Spirurida e da família Onchocercidae, transmitido por hospedeiros intermediários da família culicidae (MEIRELES et al, 2014). É conhecido popularmente como "verme do coração" ou heartworm (SILVA, 2009).

O objeto deste trabalho é estudar a fase larval (L1), conhecida por microfilária, que é a forma transmissível do parasita. Esta é mais frequente em ambientes urbanos por estes possuírem micro-climas quentes e úmidos, que favorecem a reprodução dos mosquitos (AHS, 2014).

O ciclo se inicia com a ingestão de sangue de um cão infectado com microfilárias por um mosquito da família culicidae, dentro do intestino dos mosquitos estas larvas evoluem para as fases L2 e posteriormente para L3 - a forma infectante. A L3 migra para o aparelho picador, danificando-o, e desta forma o mosquito ao picar um animal saudável deposita involuntariamente no tecido conjuntivo as larvas, as quais se deslocam para o tecido subcutâneo, onde permanecem por aproximadamente dois meses enquanto evoluem para o estágio L4, momento que adentram à corrente sanguínea e evoluem para o estágio L5 (NAGASHIMA et al, 2009). Ao chegarem no coração tendem a se fixar no ventrículo direito e passados 20 dias as fêmeas atingem a maturidade sexual, acasalam e fecham o ciclo com a liberação de novas microfilárias na corrente sanguínea (AHS, 2014).

Há o relato da ocorrência da doença em diversas espécies de animais domésticos, silvestres e no homem. Sendo os canídeos silvestres os hospedeiros naturais da doença. (SALGUEIRO et al, 2016).

Os animais infectados podem apresentar sinais clínicos variados conforme o tempo de infecção e a carga parasitária, podendo estar assintomáticos e demonstrarem sinais inespecíficos como: tosse crônica, dispnéia, intolerância ao exercício, fadiga, perda de peso e colapso agudo cardíaco. Estas complicações são decorrentes do alojamento de larvas adultas L5 na artéria pulmonar e no ventrículo 
direito (SALGUEIRO et al, 2016), que podem gerar insuficiência cardíaca direita levando o paciente à óbito (NELSON \& COUTO, 2015).

Este estudo da ocorrência de microfilária pela técnica de microhematócrito, se dá em virtude desta doença ser pouco estudada e negligenciada no Brasil (SILVA \& LANGONI, 2009), e por não se ter localizado trabalhos que abordem este tema na região do Distrito Federal (BARBOSA \& ALVES, 2006). 


\section{Fundamentação Teórica}

A revisão bibliográfica foi composta por artigos nacionais e internacionais publicados entre os anos de 1999 e 2016, com o destaque de não terem sido localizados estudos sobre a ocorrência da dirofilariose no Distrito Federal.

Os artigos analisado abordaram 5 metodologias diferentes de pesquisa de dirofilaria, dentre elas a de Levine e Wardlaw (1988), que foi metodologia utilizada neste trabalho e no trabalho de Boonyaparkon et al (2008) realizado na Tailândia, que coletou 589 amostras de sangue de cães com idade mínima de 4 meses internados no Hospital da Universidade de Chiang May que obteve uma prevalência de $18,2 \%$, e dos positivos $88,7 \%$ eram animais errantes.

Em 2014 Bhattacharjee e Sarmah realizam um estudo de identificação microscópica da fase $\mathrm{L} 1$ do parasito e pesquisa antigênica, onde dividiram cães em três categorias: domiciliados, semi domiciliados e de rua, com prevalências de 4,76; 7,95 e $29,54 \%$ respectivamente, demonstrando que quanto mais domiciliados os animais menor é a prevalência do parasito.

No Brasil, Brito et al (2001) constataram que cães, domiciliados na cidade de Maceió, quando mais próximos ao litoral maior a prevalência do parasita, sendo de $3,70 \%$ para cães mais próximos a orla e 1,18\% para cães mais distantes. Resultados que foram de encontro ao observado por Ahid et al (1999), na cidade de São Luís, onde observou que a maior prevalência de amostras positivas se deu em bairros próximo ao mar.

Em 2006, Barbosa e Alves em sua revisão de literatura, abordaram que pesquisadores observaram $2 \%$ de animais sororreagentes com a dirofilaria no estado do Mato Grosso em 1989, e em 1999 na cidade de Cuiabá foram 11,81\% sororreagentes pela $11,81 \%$ e 5,8\% por análise microscópica.

Não foram encontrados levantamentos atuais sobre a região Centro-Oeste ou estudos sobre o Distrito Federal. 


\section{Metodologia}

Foram analisadas 1.087 amostras de sangue de cães de diferentes idades as quais foram cedidas pelo laboratório veterinário Santé, localizado no Distrito Federal, durante o período de janeiro à junho de 2019. Neste estudo as amostras foram analisadas utilizando a técnica do microhematócrito, onde analisamos a capa flogística tal qual descrito por Levine e Wardlaw (1988) e utilizada por Boonyapakorn et al (2008) e o plasma sanguíneo em busca do parasito, sendo todos os resultados registrados.

As amostras, em tubos com EDTA, se originaram de diferentes regiões do Distrito Federal e foram enviadas ao laboratório Santé, que fracionou parte deste material em tubos eppendorf identificados e os disponibilizou ao para o presente estudo.

As mostras levaram de 1 a 7 dias entre a recepção no laboratório doador e a análise pela equipe deste projeto.

Ao dar entrada no laboratório deste estudo o preparo das amostras se iniciou pela homogeneização de cada amostra, a transferência do sangue armazenado do sangue de cada eppendorfs para 2 tubos capilares pelo contato direto, buscando preencher $80 \%$ do volume de cada capilar, o fechamento de uma das pontas dos tubos com material selante como recomendado por Weiser (2014) e a higienização da face externa dos capilares com auxílio de gaze e álcool $70 \%$.

Os tubos capilares foram centrifugados a $11.000 \mathrm{rpm}$ durante 5 minutos (POZZOBON, 2017), retirados da máquina, fixados em lâminas de vidro com fita adesiva e realizada pesquisa microscópica da presença de microfilária por toda a extensão do tubo capilar, com ênfase na capa flogística (BOONYAPAKORN et al, 2008; SARQUIS, 2012). 


\section{Resultados}

Após análise dos dados obtivemos 1083 resultados negativos e 5 resultados suspeitos (tabela 1).

\begin{tabular}{cccc}
\hline & Negativos & Suspeitos & Total \\
\hline $\mathrm{N}$ & 1082 & 5 & 1087 \\
$\%$ & 99,54 & 0,45 & 100 \\
\hline
\end{tabular}

Tabela 1 - Resultados das análises microscópicas

Das amostras analisadas 1 possuía resultado positivo no teste sorológico rápido, mas obteve resultado negativo na análise por capilar sanguíneo e 1 amostra obteve resultado positivo no esfregaço sanguíneo mas resultado negativo no analíse por capilar.

\section{Discussão e conclusão}

Apesar do Distrito Federal, como todo o território Brasileiro, possuir um clima favorável aos vetores transmissores da microfilária (MEIRELES et al, 2014), esta investigação pela fase L1 da microfilária no Distrito Federal obteve poucos resultados suspeitos. Os resultados foram tidos como suspeitos por não observarmos parasitos vivos e, por não termos utilizado um método mais sensível, como a sorologia.

Os dados obtidos podem ser em função da região pesquisada estar distante do litoral (AHID et al, 1999; BRITO et al, 2001), pelas amostras analisadas poderem ser predominantemente de animais domiciliares (BHATTACHARJEE e SARMAH, 2014), visto se originarem de laboratório privado. Pelo intervalo de tempo entre a coleta do material, a recepção do sangue na laboratório doador, e análise das amostras pelo projeto ter sido muito longo. Pode ainda ser considerar que o método de pesquisa utilizado possuir baixa sensibilidade (MONTAÑO et al, 2002) e que os técnicos envolvidos na pesquisa não estavam habituados a visualizarem a microfilária por microscopia.

Pesou ainda para análise dos dados o fato de não serem localizado outros levantamentos sobre este parasita no Distrito Federal, o que impediu o confronto de resultados, todavia destaca-se a importância de novos estudos que aprofundem o levantamento da fase larval L1 ou de outro estágio da Dirofilaria Immitis, no Distrito 
Federal. Entretanto os resultado obtido vão de entretanto ao proposto por trabalhos em outras regiões brasileiras (BRITO, et al 2001;LABARTHE et al. 2003). 


\section{Referências Bibliográficas}

AHID, S.M.; et al. Dirofilariose canina na Ilha de São Luís, Nordeste do Brasil: uma zoonose potencial. Cad. Saúde Pública, Rio de Janeiro , v. 15, n. 2, p. 405-412, Abr. 1999. DOI: http://dx.doi.org/10.1590/S0102-311X1999000200025. Disponível em:<http://www.scielo.br/scielo.php?script=sci_arttext\&pid=S0102-311X1999000200 025\&lng=en\&nrm=iso>. Acesso em 19 Ago. 2019.

AMERICAN HEARTWORM SOCIETY. Current Canine Guidelines for the Prevention, Diagnosis, and Management of Heartworm (Dirofilaria immitis) Infection in Dogs. 2014. Disponível em:

$<$ https://www.heartwormsociety.org/images/pdf/2014-AHS-Canine-Guidelines.pdf>. Acesso em: 10 mar. 2019.

BARBOSA, C.L.; ALVES, L.C. Dirofilariose canina: situação atual no Brasil. Revista do Conselho Federal de Medicina Veterinária, v.1, p.57-62, 2006.

BHATTACHARJEE, K; SARMAH, P. Epidemiological Aspects of Dirofilaria immitis Infection in Dogs from Assam of Northeast India. Asian Pacific Journal of Tropical Disease, v.4, p.255-258, 2014. DOI: https://doi.org/10.1016/S2222-1808

BOONYAPAKORN, C.; et al. The epidemiology of Dirofilaria immitis infection in outpatient dogs at Chiang Mai University Small Animal Hospital, Thailand. Southeast Asian J Trop Med Public Health, v.39, n.1, jan. 2008.

BRITO, A.C.; et al . Prevalência da filariose canina causada por Dirofilaria immitis e Dipetalonema reconditum em Maceió, Alagoas, Brasil. Cad. Saúde Pública, Rio de Janeiro , v. 17, n. 6, p. 1497-1504, Dez. 2001 . DOl: http://dx.doi.org/10.1590/S0102-311X2001000600021. Disponível em:<http://www.scielo.br/scielo.php?script=sci_arttext\&pid=S0102-311X2001000600 021\&lng=en\&nrm=iso>. accesso em 19 Ago. 2019. 
GUERRERO, J. et al. Recent advances in heartworm disease. Veterinary parasitology, v. 125, n. 1-2, p. 105-130, 2004.

KNOTT, J., 1939. A method for making microfilarial surveys on dog blood. Transactions of the Royal Society Tropical Medicine and Hygiene, 33:191-196.

LABARTHE, N. et al. Serologic prevalence of Dirofilaria immitis, Ehrlichia canis, and Borrelia burgdorferi infections in Brazil. Veterinary therapeutics: research in applied veterinary medicine, v. 4, n. 1, p. 67-75, 2003.

LEVINE R.A.; WARDLAW S.C. A new technique for examining blood. Am Scientist, v.76, p. 592-8. 1988.

LEITE, L.C.; et al. Prevalência de Dirofilaria immitis (Leidy, 1856) em cães do Canil Municipal de Guaratuba, Paraná, Brasil. Estudos de Biologia, v. 29, n. 66, 2007.

MEIRELES, J.; et al. Dirofilariose canina e felina. Revista Portuguesa de ciências veterinárias, v.109, p.70-78, 2014.

MONTAÑO, José Manuel Ferrer et al. Diagnóstico de dirofilariosis canina: un estudio comparativo usando las pruebas de ELISA y de Woo. Revista Científica de la Facultad de Ciencias Veterinarias, v. 12, n. 5, p. 351-358, 2002.

NAGASHIMA, J. C.; et al. Dirofilariose. Revista Científica Eletrônica de Medicina Veterinária, Ano VII, n 12, p. 7, 2009.

NELSON, R.W.; COUTO, C.G. Medicina interna de pequenos animais. 5.ed. Rio de Janeiro: Guanabara Koogan, 2015.

POZZONI, A. Biomedicina na prática: da teoria à bancada, 1,ed. Lajeado : Ed. da Univates, 2017. 
SALGUEIRO, J.M.; et al. Dirofilariose Canina. Tese (Mestrado em Medicina Veterinária) - Faculdade de Medicina Veterinária, Universidade Lusófona de Humanidades e Tecnologias. Lisboa, p.64. 2016.

SARQUIS, J. G. Dirofilariose (Dirofilaria immitis) em Cães e Gatos. 2012. 110 p. Monografia (Graduação em Medicina Veterinária)-Universidade de Brasília - UnB, Brasília, 2012.

SILVA, R. C.; LANGONI, H. Dirofilariose: zoonose emergente negligenciada. Ciência Rural, v.39, p. 1614-1623, 2009.

WEISER, G. Tecnologia Laboratorial em Medicina Veterinária. In: THRALL, M. A. et al. Hematologia e Bioquímica Clínica Veterinária, $2^{a}$ edição. Rio de Janeiro: Roca, 2014. Cap. 1. p. 22-86.

WALTERS, L. L. et al. Risk factors for heartworm infection in Northern California. In:

Proceedings of the heartworm symposium, Auburn, Alabama, USA, 31 March-2nd April, 1995. American Heartworm Society, 1995. p. 5-26. 
